\title{
Introducing Geosciences in a blended Education Master degree
}

\author{
Huguet, Carme $^{\text {a }}$; Francisco Blanco-Quintero, Idael ${ }^{\text {; }}$ Henao Mejía, Martha Cecilia ${ }^{\text {; }}$; \\ Moreno Vela, Francy Julieth ${ }^{c}$; Chimbí Sanchez, Lizeth Andrea \\ ${ }^{\mathrm{a}}$ Geoscience department, Universidad de los Andes, Colombia, ${ }^{\mathrm{b}}$ Departamento de Ciencias \\ de la Tierra y del Medio Ambiente, Universidad de Alicante, Spain ${ }^{c}$ Conecta-TE Center on \\ education innovation, Universidad de los Andes, Colombia.
}

\begin{abstract}
We aimed to introduce geoscience to a group of primary and secondary teachers without previous knowledge of the subject, since this branch of science has only recently been included in the science basic program. While all students had completed university education, none had any geoscience background, thus the course was designed at a basic level. Contents and activities were carefully selected to provide a good introduction to geosciences giving the students the basic concepts and letting them apply new knowledge within a problem based strategy. Since the students of the module work full time, the master was designed in a blended format providing flexibility of work hours. The blended model also helped students from the wide geographical region interact and form long lasting collaborations. Students reported that collaborative learning was necessary and key to their learning process. They also stated that the contents of the course were sufficient, clear, organized and interesting. We view the module as a success since all students reported enjoying the module and building novel knowledge in the field of geosciences. Additionally since the students are in turn teachers we were very happy to learn some of them will implement geosciences in their activities in the future.
\end{abstract}

Keywords: Blended education; problem based learning; active pedagogy; collaborative learning; master; geoscience 


\section{Introduction}

We present the implementation of a geoscience module within a Physics and Geoscience course, for a blended Master in Education, imparted by the Andes University, Bogotá, Colombia. The Geoscience module had 18 students who are school and high school teachers in full time employment in the Tolima Department (Fig. 1). The students present a range of educational backgrounds (Fig. 1a) and teach a variety of subjects at their institutions Fig. 1b).
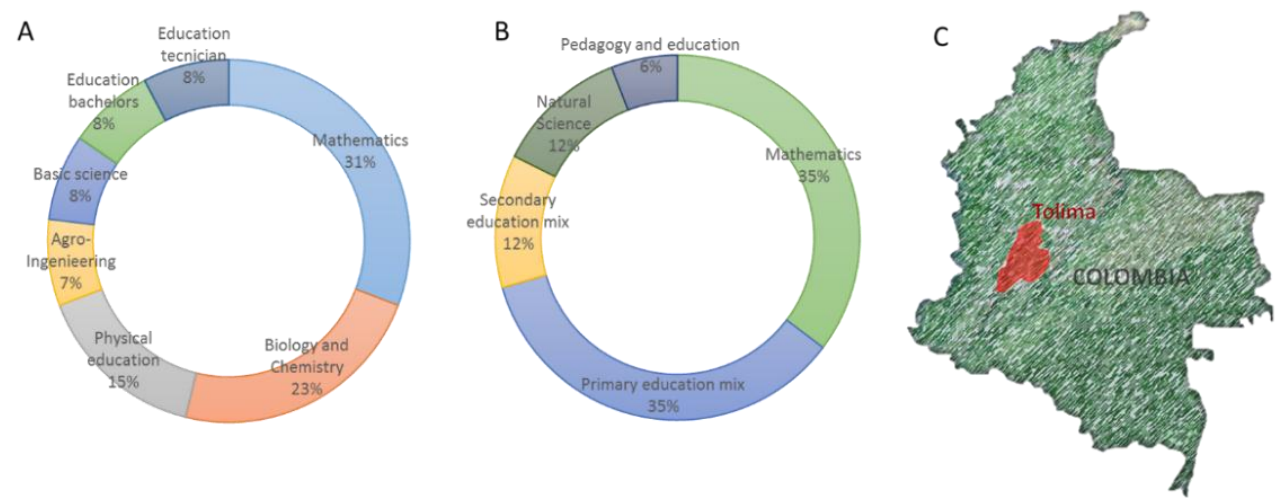

Figure 1. Description of student population taking the blended Master on Education imparted by the Universidad de Los Andes in Ibague, Tolima; A)Education that the students had when starting the master; B) Classes the students impart on their own institutions; C)Map of Colombia, the Tolima region has been highlighted in red.

While geoscience is part of the basic science knowledge it has only recently been included in the education guidelines from the Colombian government (Ministerio de Educación de Colombia 2006). Therefore the students of the blended Education master had no previous knowledge of earth sciences.

The geoscience module contents follow the guidelines of the Ministry of Education of Colombia about the application of geoscience concepts in the different courses at school and high school level (Ministerio de Educación Nacional de Colombia, 2006). The idea was to make the content challenging for professionals that already completed university degree (Fig. 1a) but at the same time accessible and interesting to none specialist (e.g. Yuretich, 2001). We also had the challenge to introduce a completely new subject to the students since geosciences is not included in the basic education in Colombia.

The main challenges of the blended module in geosciences were 1) offer the means for the students to combine their daily workload with studying a master; 2) promote collaborative learning; 3) deliver in 8 weeks a basic education in earth sciences to a very heterogeneous 
student base; 4) use a range of activities that aided effective learning. The first and second challenges was addressed through blended learning strategies (Graham 2006).

While many definitions have been suggested, blended learning could be defined as an approach that integrates web-based teaching and learning mode with face-to-face interaction (see Maarop and Embi, 2016 for review). Blended learning is supposed to improve student participation, but issues like poor time management or lag of interaction with peers and teachers have been reported in some instances (Graham, 2006; Maarop and Embi, 2016 and references therein). This was the reason the module was designed to promote collaborative learning within a blended format.

The concept of collaborative learning, though student pairing to achieve an academic goal has been widely researched and advocated (e.g. Dillenbourg, 1999). The term "collaborative learning" can be defined as a method in which students work together in small groups toward a common learning goal (e.g. Dillenbourg, 1999). Even though online activities can be collaborative, the in site classes are considered key in developing synergies between the students (Graham, 2006; Maarop and Embi, 2016).

Finally we wanted students to engage in active learning, as it provides greater appropriation of knowledge and deeper understanding based on synthesising, critically assessing and transforming basic knowledge, which can be seen as 'learning better' (e.g.Yuretich 2001; Freeman et al. 2014). For that professor IFBQ selected a range of activities that required applying the knowledge acquired to solve problems. Problem-based learning has been proven to increase learning and improve retention (e.g. Yuretich, 2001). In the present case the project on Rocks from the Tolima region (where the students came from; Fig. 1c) is a great example of problem based learning.

\section{Methods}

\subsection{Structure of the module}

The Geoscience module took place between the $1^{\text {st }}$ of October and the $26^{\text {th }}$ of November 2017, starting on week 9 of the master's second semester (Table 1). Three in site sections were included (shown by stars in Table 1) on Saturdays from 7 to $10 \mathrm{am}$. The module was divided in 3 content sections, 1) Earth origin, structure and plate tectonics; 2) Volcanos, earthquakes, minerals and rocks; and 3) Life origin, fossils and geological time (Table 1). 
Table 1. Timeline of the course with the contents covered during the week period of the Geoscience module. Stars indicate on-site lectures by $\mathrm{CH}$.

\begin{tabular}{|c|c|c|c|c|c|c|c|c|}
\hline Content Covered & W-9 & W-10 & W-11 & W-12 & W-13 & W-14 & W-15 & W-16 \\
\hline Earth Origin, Structre and plate tectonics & 太 & & & & & & & \\
\hline Volcanoes, Earthquakes, Minerals and Rocks & & & & & $\star$ & & & \\
\hline Life origin, Fossils and Geological scale & & & & & & & & $\star$ \\
\hline
\end{tabular}

\subsection{Tools for evaluation}

Students undertook an online survey in order to evaluate a range of qualitative aspects related to the learning environments of the module. The team at Conecta-te (Center on education innovation), Los Andes University, Colombia, developed a survey to measure the key conditions of learning blended environments using the Likert scale (Likert, 1932). The Likert scale was developed in 1932 as the familiar five-point bipolar response that most people are familiar with today (Likert, 1932). The scale assigns a numerical value of (1) totally disagree; (2) disagree; (3) nor agree or disagree; (4) agree and (5) totally agree.

\section{Results and discussion}

While many aspects of were evaluated, in line with our objectives for the module, we will focus on 1) collaborative learning and interaction; 2) the quality of the geoscience module contents and 3 ) the contribution of the proposed activities to the learning process.

\subsection{Collaborative learning and interaction:}

Collaborative work is essential to improve knowledge acquisition and student motivation (e.g. Dillenbourg, 1999; Attard et al. 2010). In fact, collaborative learning has been shown to enhance many transversal skills such as critical thinking or teamwork. However, this type of learning is challenging when working on a blended context (e.g. Maarop and Embi, 2016). Many of the e-activities were selected to foster interaction with peers and the teacher. 


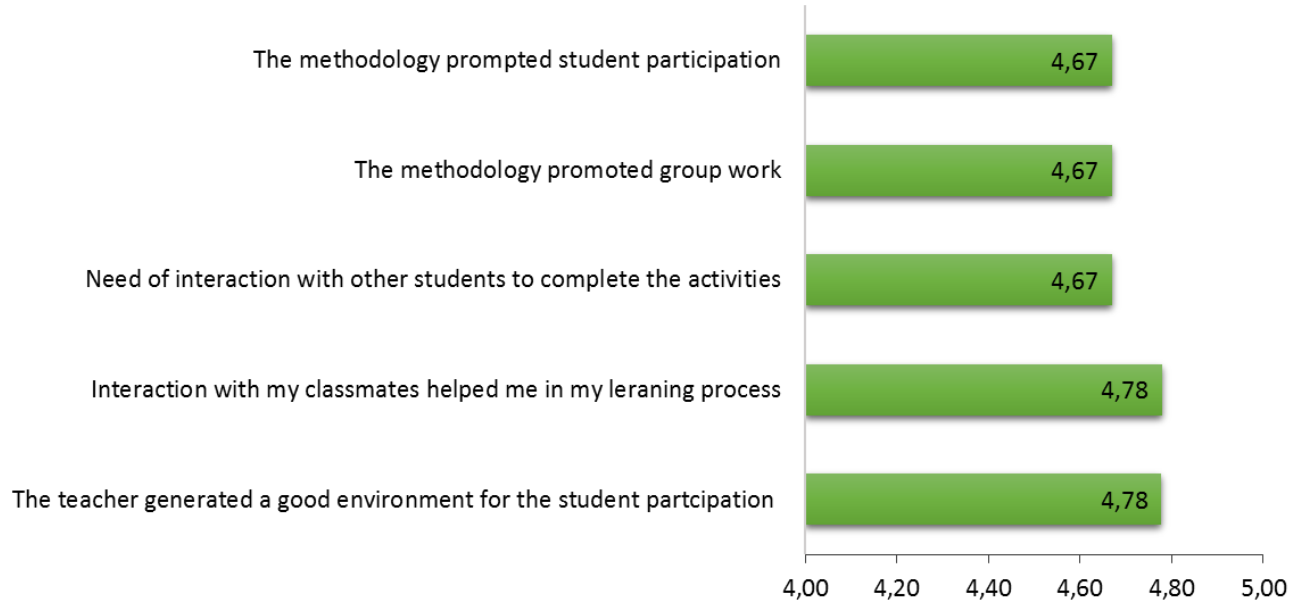

Figure 2. Perceptions of collaboration and interaction within the Geoscience module. Likert scale of evaluation is from 1 to 5 but has been enhanced to start from 4 since all values are above that.

Students rated how the methodology prompted student participation and group work with a 4.67 (Fig. 2). It was found in previous projects that group homework assignments were less effective in promoting teamwork, since group homework was usually undertaken by one enthusiastic student or divided among team members to undertake individually $(\mathrm{CH}$ personal observation). Therefore, the activities in the master module were designed so they would require interaction between group members to be completed and were successful in that respect with a 4.67 mark allocated by the students (Fig. 2).

A key component of collaborative learning is that students are responsible for their peers' learning as well as their own and the success of one student helps the others to be successful (Dillenbourg, 1999). The interaction with their peers was rated in 4.78 as helping them with their learning (Fig. 2), thus confirming the importance of teaching between pairs and the adequacy of the module design to achieve that goal.

\subsection{Quality of Geoscience Module contents}

Since the introductory geosciences course at Andes University is all face-to-face and additionally has a much higher credit load, designing the contents and activities of the module in the education master was challenging. Professor IFBQ together with Conecta-te, course developer MCHM designed the course to cover three main areas of the geosciences according to the Ministerio de Educación de Colombia (2006) published guidelines (Table 1). They selected activities that would help integrate the novel concepts acquired by the 
students to the construction of knowledge in geosciences and that would require active learning.

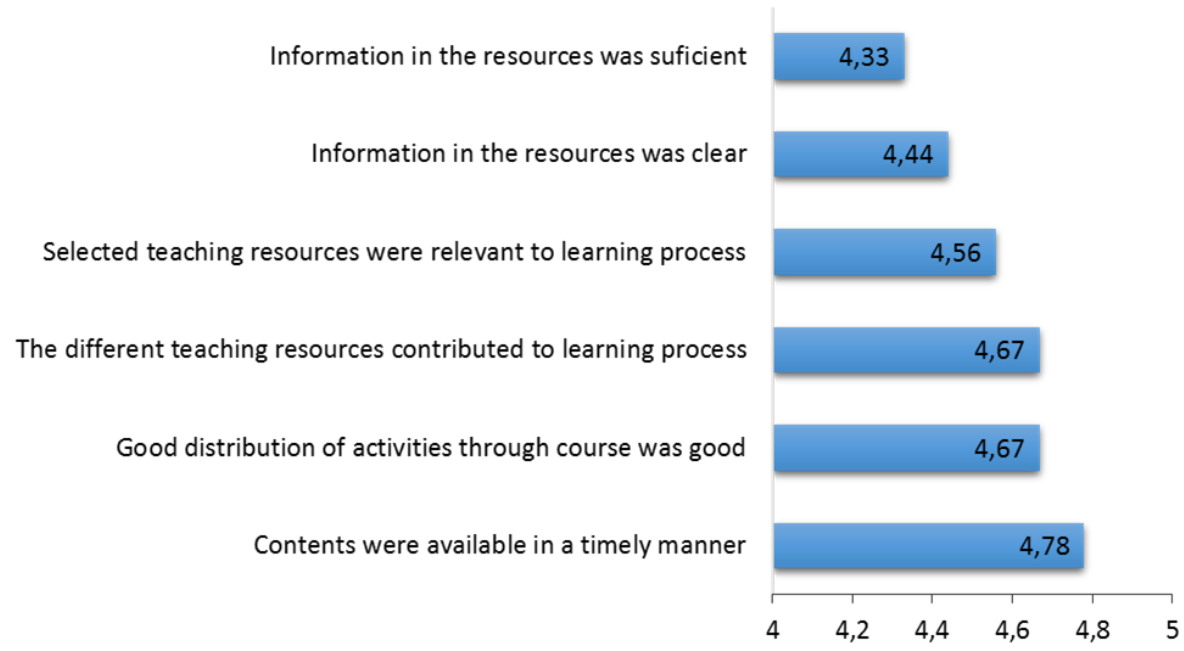

Figure 3. Student evaluation of course contents based on clarity, variety and quality. Likert scale of evaluation is from 1 to 5 but has been enhanced to start from 4 since all values are above that.

The information provided was considered sufficient (4.33; Fig. 3) and clear (4.44; Fig. 3) which was one of the challenges faced by the module designers in teaching geoscience to that particular student base (Fig. 1a). The resources included a range of videos and an introduction to geoscience book (Tarbuck et al. 2005), the students were encouraged to find other materials independently. The students agreed that the selected resources were relevant (4.56; Fig. 3) and contributed to their learning process (4.67; Fig. 3). Additionally the contents were readily available (4.87; Fig. 3 ) and well distributed through the course (4.67; Fig. 3). Thus, in general the contents were very highly rated and viewed to be conductive significantly to the learning process.

\subsection{Contribution of the proposed activities to the learning process}

In terms of aiding the learning process the proposed activities were rated between 4.22 and 4.89 (Fig. 4). While the participation on an online forum was rated the lowest (4.22, Fig. 4) it is still highly rated as conductive to their learning. That is even more positive when we consider that some of the students had limited access to internet during the week, which has been shown to hamper blended strategies (Maarop and Embi, 2016).

Even though two different tools, Wiki pages and Paddlet, were used by the students to produce online material, students rated them equally with a 4.56 (Fig. 4) for their 
contribution to their learning process. Groups were picked randomly and were different for the two activities and the contribution of all members of the group was assessed.

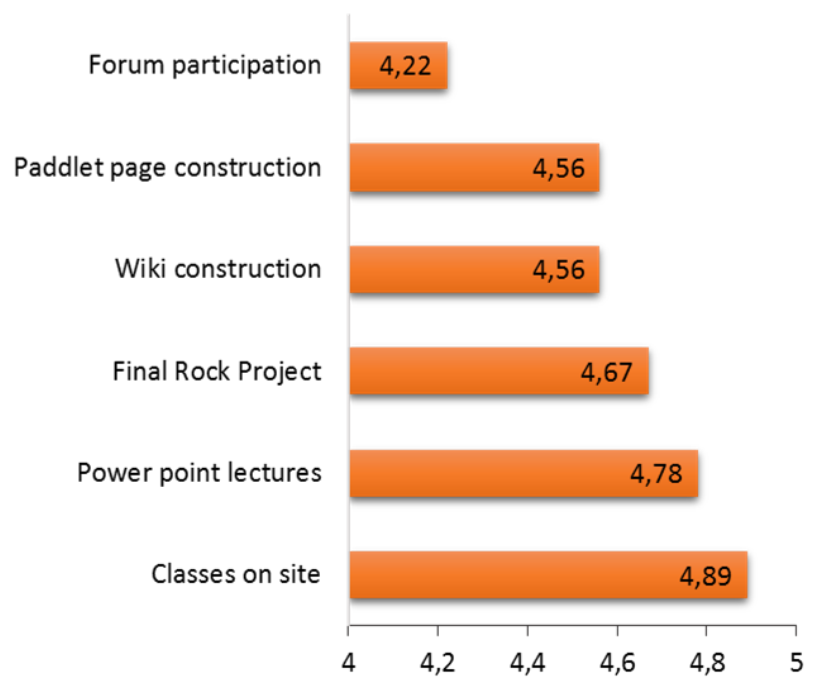

Figure 4. Contribution of activities proposed during the geoscience module to students' learning process. Likert scale of evaluation is from 1 to 5 but has been enhanced to start from 4 since all values are above that.

The final project to study Rocks from the Tolima area was introduced as a departure from the traditional 'spoon-feeding' teaching, promoting student's active work through realistic and challenging project. It has been shown that applying knowledge to complete a project results in better learning and higher motivation (e.g. Sodupe-Ortega et al. 2017). In the present case we were tapping into the intrinsic motivation, which is related to the "human propensity to learn and assimilate" (Ryan and Deci, 2000) to provide a more fulfilling and meaningful learning. The fact that the project was based on the area of residence and work of the students made it even more relevant to them with a 4.67 evaluation (Fig. 4) on the contribution it made to their learning process. Some of the students involved their pupils in the sample collection thus resulting on a trickle down strategy not anticipated by the course designers.

Still the highest rated activities were those done in class with the power point lectures attaining a 4.78 and the teacher performance a 4.89 (Fig. 4). Thus, the direct interaction with the teacher was crucial to the success of the Geoscience module and the learning process of the students. Justifying the need for a blended strategy rather than a fully online one. 
Additionally the articulation between in class and online activities was considered good by $89.9 \%$ of the students with a mark of 4.44 on the Liker scale.

\section{Conclusions}

The Geoscience module received very good ratings from the students with no evaluation below 4.22. This is specially fulfilling since the students are education professionals themselves.

The design of the course was successful in making accessible the novel geoscience subject to all the students in the master, as demonstrated by the fact that all of them passed the module (data not shown).

The choice of activities both online and in class achieved our goal to foster collaborative work and interaction both among students and between students and teacher.

The proposed activities were considered pertinent and conductive to learning by all students in the class.

Additionally since the students are in turn teachers we were very happy to learn some of them will implement geosciences in their activities in the future. Making this experience a success also in disseminating that subject on the country.

\section{References}

Attard, A., Di Iorio, E., Geven, K., \& Santa, R. (2010). Student-Centred Learning: Toolkit for Students, Staff and Higher Education Institutions. European Students' Union (NJ1).

Freeman, S., Eddy, S. L., McDonough, M., Smith, M. K., Okoroafor, N., Jordt, H., \& Wenderoth, M. P. (2014). Active learning increases student performance in science, engineering, and mathematics. Proceedings of the National Academy of Sciences, 111(23), 8410-8415.

Graham, C. R. (2006). Blended learning systems. The handbook of blended learning, 3-21.

Likert, R., (1932). A Technique for the Measurement of Attitudes, Archives of Psychology, $140,5$.

Maarop, A. H., \& Embi, M. A. (2016). Implementation of blended learning in higher learning institutions: A review of literature. International Education Studies, 9(3), 41.

Ministerio de Educación de Colombia (2006). Estándares Básicos de Competencias en Lenguaje, Matemáticas, Ciencias y ciudadanias: guía sobre lo que los 
estudiantes deben sabler y saber hacer con lo que aprenden. Bogotá, D.C: MEN. Recuperado de: http://www.mineducacion.gov.co/1621/340021_recurso_1.pdf

Dillenbourg, P. (1999). What do you mean by collaborative learning? 1-19pp.

Ryan, R.M. \& Deci, E.L. (2000). Intrinsic and Extrinsic Motivations: Classic Definitions and New Directions. Contemporary Educational Psychology 25: 54-67. doi:10.1006/ceps.1999.1020.

Sodupe-Ortega, E., Martinez-de-Pison-Ascacibar, F. J., Urraca, V., Antonanzas-Torres, J., \& Sanz Garcia, A. (2017). Assessment of microproject-based teaching/learning (MicroPBL) experience in industrial engineering degrees. In HEAd' 17 proceedings of the 3rd international conference on higher education advances.

Tarbuck, E. J., \& Lutgens, F. K. (2005). Ciencias de la Tierra: Una introducción a la geología física, $8^{\text {va }}$. Edición.

Yuretich, R. F., Khan, S. A., Leckie, R. M., \& Clement, J. J. (2001). Active-learning methods to improve student performance and scientific interest in a large introductory oceanography course. Journal of Geoscience Education, 49(2), 111-119. 